\title{
PREDICTIVE FACTORS OF HEALTH DISCHARGE OUTCOMES FOR COLORECTAL CANCER PATIENTS IN A ROMANIAN HOSPITAL
}

\author{
ANAMARIA NICOLETA CRENGUȚA PETRIȘOR ${ }^{1}$, ALINA IOANA FORRAY ${ }^{2}$, \\ CRISTINA MARIA BORZAN ${ }^{3}$, BOGDAN FLORIN COVALIU ${ }^{4}$, FLORINA GABOR- HAROSA \\ CARMEN DANIELA DOMNARIU
}

1,2,3,4,5 “Iuliu Hațieganu” University of Medicine and Pharmacy, Cluj Napoca, ",6 "Lucian Blaga” University of Sibiu,

"Babeș-Bolyai" University, Cluj Napoca

\begin{abstract}
Keywords: colorectal Abstract: In-hospital data on colorectal cancer from Romania demonstrate differences from other cancer, discharge European countries, especially in the mean age of patients, discharge rates and length of stay. Our planning, predictive study aimed to investigate possible factors that could predict the health outcomes at the discharge of modelling, logistic colorectal cancer patients hospitalized in a Romanian county hospital. We retrospectively analysed regression 9009 colorectal cancer patients from a Romanian County Hospital. The model of binary logistic regression, a stationary or aggravated discharge disposition was associated with patients with age equal or higher than 60 years $(p=0.002)$, the nonretirement status of patients $(p=0.004)$, discharge from a surgical section ( $p=0.000)$, a surgical procedure performed during the hospitalization period $(p=0.000)$ and a hospitalization period shorter than seven days $(p=0.000)$. Potentially actionable demographic and hospital-level characteristics can predict colorectal cancer health outcomes of patients at discharge. Knowledge of this information would allow for several strategies that could improve the discharge planning.
\end{abstract}

\section{INTRODUCTION}

The disease burden of cancer in Europe has been increasing over time, and population ageing is a major contributing factor to this development.(1) Colorectal cancer is a significant worldwide public health problem, and the foreseen rise in the burden of disease related to economic and demographic transition is connected with widening disparities among and within countries.(2) Based on the GLOBOCAN estimations from 2018 of colorectal cancer incidence and mortality, produced by the International Agency for Research on Cancer, colorectal cancer ranked second in Europe in terms of incidence and mortality, with approximately 500,000 new cases diagnosed only in Europe, and 243.000 deaths. Based on this report, Romania had the 29th highest age-standardized incidence for both sexes, at all ages from Europe (26,7 cases per 100.000 individuals). Nevertheless, it had 12th highest age-standardized mortality rate in the European area $(13,7$ cases per 100.000 individuals). The 5-year prevalence from 2013-2018 increased to a total of 30.000 cases.(3)

Based on 2020 study of in-hospital data from Romania, the CRC mortality is much higher than the EU mean mortality, because of a probable delayed diagnosis due to the lack of well-managed screening program. The same study concluded that Romania has the highest discharge rates for colorectal cancer in Europe for the years between 2015-2018, and one of the most extended average lengths of stay, determined by a probable more severe stage of the disease.(4)

As well, a significant issue found is the high mean age of hospitalized CRC patients from Romania.(4) Older patients have often medical comorbidities and negative results, associated with post-treatment morbidity and mortality. $(5,6)$ Elderly discharged CRC patients do not receive appropriate care needs, including functional deficits, social and emotional assistance, and economic resources to manage their recovery. Additionally, when post-discharge care plans do not adequately address the deterioration of physical function, there is an increased risk of readmission, leading to raised expenses for patients and health care systems.(7) More elderly patients are undergoing surgery because the progress in surgical and anaesthetic procedures have made it more secured to operate even in frail patients.(7)

Surgery is the current treatment for resectable colorectal cancer, and during the last decade, it has experienced some significant improvements on pre-operative assessment, instrument, surgical techniques, intra-operative monitor and post-operative care.(8)

\section{AIM}

We performed this study to investigate possible factors that could predict the health outcomes at the discharge of patients hospitalized and diagnosed with colorectal cancer. At the health system and hospital level, knowledge of this information would allow for a number of strategies that could possibly advance the quality and effectiveness of rehabilitation pathways and discharge planning. For example, preoperative risk stratification could identify a high-risk cohort for whom early, evidence-based interventions designed to prevent negative discharge outcomes could be implemented.(9) We hypothesize

${ }^{2}$ Corresponding author: Alina-Ioana Forray, Str. Romulus-Vuia, Nr. 213, Cluj-Napoca, România, E-mail: alina.forray@publichealth.ro, Phone: +4075 1331716

Article received on 21.04.2020 and accepted for publication on 28.05.2020 


\section{PUBLIC HEALTH AND MANAGEMENT}

that readily available health information from hospital records could help physicians with better decision making in managing these patients. These factors could then be useful to plan a surgical or non-surgical CRC patient's discharge, increase efficiency and improve resource allocation.

\section{MATERIALS AND METHODS}

Data source

A secondary analysis was performed retrospectively reviewing the medical registry from the Regional Institute of Gastroenterology Hepatology Prof. Dr. "Octavian Fodor", ClujNapoca. The hospital database contains clinical, demographic and administrative data from 2009 to 2018, of a total of 9009 patients with colorectal cancer. It includes the typical information of patients that were hospitalised and discharged in this time frame. The appropriate institutional review board approved the use of the database information for research at the Regional Institute. It includes the use of operational level data on clinical sections (admission and discharge), the period of hospitalisation (the dates for admission, surgical intervention and discharge) and variables dependant on the type of admission (criterion, county health insurance house, kind of admission, service transfer). As well, it includes clinical data, like ICD-10$\mathrm{CM}$ diagnoses and the name of the surgical intervention and several demographics measures (sex, age, educational level, residence information, and assurance type).

\section{Sample selection}

We included all adult subjects, aged 18 years or older, cared for by the following units: gastroenterology, internal medicine and general surgery, during their admission. The study period was defined as January 2009 through December 2018 Because of the lack of identification variables, independence of observations was not ensured, and there is the possibility that subjects were included in the analysis multiple times in different years. The exclusion criteria included subjects under the age of 18 and subjects whose discharge diagnoses were not colorectal cancer. The final sample included for analysis included 9009 subjects for the main study, and the final selected cases for the logistic regression model included 5238 patients (58.1\%), because of the missing data.

\section{Data analysis}

Descriptive statistics were calculated for sociodemographic data, as well for administrative and clinical data from 9009 subjects included in the analysis. These data were described as frequencies and per cent. For data referring to age, central tendency and dispersion were measured as mean and standard deviation. For the inferential analysis between sociodemographic clinical and administrative data, the Chi-Square test was used to calculate the effect size with odds ratio. This test was used for comparison and association using the frequency of categorical data between the different subsamples.

A model of binary logistic regression was performed to assess the impact of a number of factors on the overall health state of patients when they were discharged home from the hospital. It was used between the several independent variables and the dependent variable, coded as subjects' state at discharge stationery, aggravated or deceased (1) and improved or cured $(0)$.

Linear Modelling was utilised to create an explicative analysis model of the association power between the independent variables and the discharge dispostion. It allows testing of the null hypotheses about the effects of other factors on the means of a single dependent variable. For regression analysis, the independent (predictor) variables are specified in table no. 1 . To verify the adequacy of this integrated model, the Hosmer-Lemeshow model for goodness of fit test was applied, with a $\mathrm{p}$-value of $\mathrm{p}=0.236$, indicating a good fit for the model. A p-value of $<0.05$ was used to indicate statistical significance. All analyses were performed on SPSS (Version 22).

Table no. 1. Coding of independent variables used in the binary logistic model

\begin{tabular}{|l|l|l|}
\hline \multirow{2}{*}{ Sex } & Males & 1 \\
\cline { 2 - 3 } & Females & 0 \\
\hline \multirow{2}{*}{ Age } & Age equal to or over 60 years & 1 \\
\cline { 2 - 3 } & Age under 60 years & 0 \\
\hline \multirow{2}{*}{ Retirement status } & Not retired patients & 1 \\
\cline { 2 - 3 } & Retired patients & 0 \\
\hline \multirow{2}{*}{ Place of residence } & Urban area & 1 \\
\cline { 2 - 3 } & Rural area & 0 \\
\hline \multirow{2}{*}{ Hospitalisation duration } & Duration under 7 days & 1 \\
\cline { 2 - 3 } & Duration equal to or over 7 days & 0 \\
\hline \multirow{2}{*}{ Admission criteria } & Medical-surgical emergencies & 1 \\
\cline { 2 - 3 } & Other admission criteria & 0 \\
\hline \multirow{2}{*}{ Admission unit } & Surgical unit & 1 \\
\cline { 2 - 3 } & Non-surgical unit & 0 \\
\hline \multirow{2}{*}{ Discharge unit } & Surgical unit & 1 \\
\cline { 2 - 3 } & Non-surgical unit & 0 \\
\hline $\begin{array}{l}\text { Performing surgical } \\
\text { procedure }\end{array}$ & With surgical procedure & 1 \\
\cline { 2 - 3 } & Without surgical procedure & \\
\hline
\end{tabular}

\section{RESULTS}

\section{Sample description}

Socio-demographic characteristics for the 9009 cases of colorectal cancer are presented in table no. 2. Linear Modelling was utilised to create an explicative analysis model of the association power between the independent variables and the discharge disposition, ranging from 18 to 97 years of age (SD = $10.89)$. From the results, it is clear that most patients were retired $(46.5 \%)$ and lived in an urban area (49.6\%). Figure no. 1 which shows the population pyramid of the sample key findings emerge: colorectal cancer is more prevalent in males $(57.9 \%)$ than in females (42.15); most patients $(51 \%)$ were in the age group of 55-69 years, while only a minority of $17.2 \%$ were between 18 and 54 years. The mean age of the patients with colon cancers was significantly higher than the age of those with rectal cancer $(64.45$ vs. 63.40 years, $p<0.0001)$. As well, patients with left-sided tumours were significantly younger than those diagnosed with right-sided tumours (64.96 vs. 64.27 years, $\mathrm{p}=0.024)$.

Table no. 2. Characteristics of the sample

\begin{tabular}{|l|l|c|c|}
\hline Characteristics & Categories & $\mathbf{N}=\mathbf{9 0 0 9}$ & $\mathbf{\%}$ \\
\hline \multirow{3}{*}{ Gender } & Females & 3794 & 42.1 \\
\cline { 2 - 4 } & Males & 5215 & 57.9 \\
\hline \multirow{5}{*}{ Residenceries of } & Students & 13 & 0.1 \\
\cline { 2 - 4 } & Unemployed & 281 & 3.1 \\
\cline { 2 - 4 } & $\begin{array}{l}\text { Freelancer or self- } \\
\text { employed }\end{array}$ & 64 & 0.7 \\
\cline { 2 - 4 } & $\begin{array}{l}\text { Employed or } \\
\text { business owner }\end{array}$ & 1123 & 12.4 \\
\cline { 2 - 4 } & Retired & 4193 & 46.5 \\
\cline { 2 - 4 } & Missing data & 3335 & 37 \\
\hline & Rural area & 1954 & 21.7 \\
\cline { 2 - 4 } & Urban area & 4468 & 49.6 \\
\cline { 2 - 4 } & Missing data & 2587 & 28.7 \\
\hline
\end{tabular}

At admission, a small percentage of cases were diagnosed with other ICD-10 CM codes than those for colorectal cancer $(\mathrm{N}=1164,12.92 \%)$, from whom 229 had only signs and symptoms related to the digestive system or general signs. The commonest primary at discharge site was the colon $(\mathrm{N}=4833$, $53.64 \%)$, followed by the rectum $(\mathrm{N}=3227,35.8 \%)$ and the recto-sigmoid junction $(\mathrm{N}=949,10,5 \%)$.

From the inpatient hospitalisation administrative data, the mean duration of hospitalisation was 8.15 days $(\mathrm{SD}=6.227)$ and a median of 7 days. However, 27,2\% were hospitalised only 


\section{PUBLIC HEALTH AND MANAGEMENT}

between 2 and 4 days, while around $5 \%$ of the cases were hospitalised between 20 and 93 days. From the total sample, for 5407 patients $(60,01 \%)$ surgical procedures were performed. Most patients $(49,2 \%)$ were admitted to the hospital-based on a medical referral note from the general physician, followed by those who were referred by a specialist physician $(28,3 \%)$. Around $20 \%$ of patients did not have any medical recommendation and were admitted based on emergency criteria. The majority of the sample were admitted to the general surgery unit $(62.2 \%)$, while $19,3 \%$ and $18,5 \%$ were admitted to the gastroenterology unit, respectively to the internal medicine unit. It is important to note that the majority of patients $(58,3 \%)$ had an improved health state at discharge, while more than $20 \%$ were noted as cured. Almost 19\% remained stationary during the hospitalisation period, and $0.5 \%$ had an aggravated state of disease. The rate of hospitalised patients that died in our sample was $1.8 \%$.

Figure no. 1. Population pyramid of the sample of colorectal cancer patients

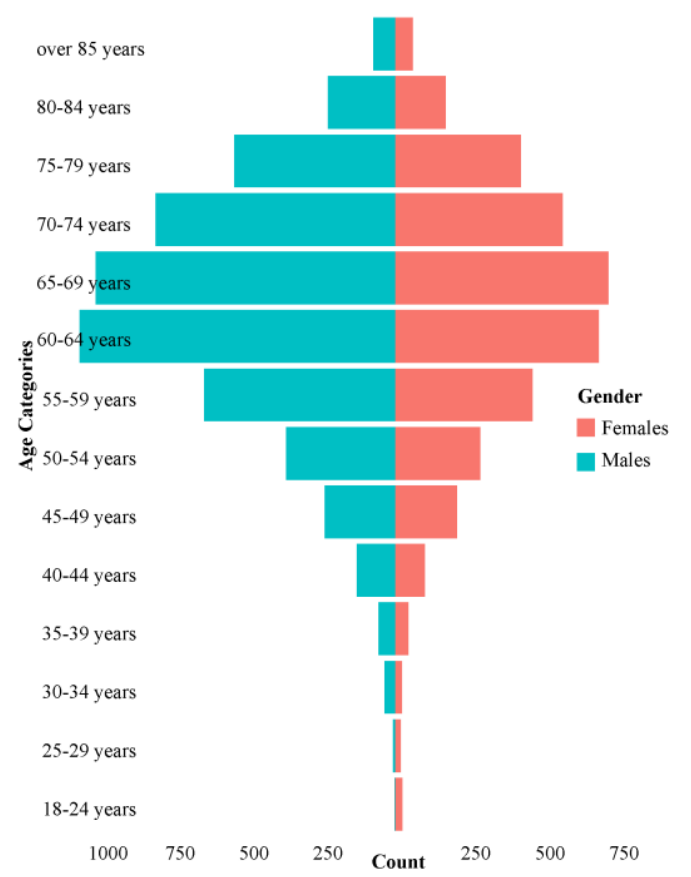

Inferential analysis

Certain socio-demographic and administrative data from the medical registry database have been identified and included as predictor variables in a binary logistic regression model (table no. 3). The analysis was carried out in order to assess the impact of these factors on the likelihood that the colorectal cancer patient would have a stationary / worsen state of health at discharge or dying during the hospitalisation period, or an improved or cured health status at discharge. The applied model with all predictors was significant, with $\chi 2=819.626(\mathrm{df}$ $=9, \mathrm{~N}=5238, \mathrm{p}<0.0001)$. The general accuracy of this model to predict patients having a stationary/worsen state of health at discharge with a predicted probability of 0.5 is $82 \%$, indicating that this model is capable of distinguishing between patients diagnosed with colorectal cancer and their discharging outcomes. The sensitivity of the current model is $98.6 \%$, while the positive predictive value is $54.6 \%$ and the negative predictive value $=82.67 \%$.

Based on the odds ratio value, the probability of having a stationary/worsen state of health at discharge increases approximately 1.5 times in patients with age equal to or over 50 years and in those that are not retired. It seems that sex and residency of the patients do not influence the health state significantly at discharge. The administrative data that were linked to an increased probability of this result were the discharge from a surgical section, surgical procedures and a shorter hospitalisation period. The probability increases more than 6.5 times for the patient who had a surgical procedure during the hospitalisation period. As well, compared to those who were discharged from the gastroenterology or internal medicine unit, those discharged from a surgical unit were approximately three times more likely to have a stationary/ worsen state of health. Apart from these factors, another important variable is the duration of the hospitalisation. The logistic regression model demonstrated that patients hospitalised less than seven days were more than two times likely not to improve their health state. Our results cast a new light on the effect of the length of stay on the health state at discharge.

\section{DISCUSSIONS}

The incidence of colorectal cancer increased dramatically in Romania and worldwide, is one of the highest in Europe. In Romania, recent trends from 2018 reported twice as many deaths than the European Union average. As well, the prevalence of Romanian patients diagnosed with colorectal cancer that are hospitalized continuously increased in the last years.(4) It is, therefore, a priority to ensure appropriate discharge planning for these hospitalized patients and to improve patient flow due to the rising demand for services and the economic burden of this disease. The results demonstrated in this study confirm the importance of specific patient and hospital characteristics on the health state of colorectal patients at discharge. It is worth discussing these pieces of evidence revealed by the results of the logistic regression model.

Colorectal cancer, in particular, is mostly a disease of ageing.(10) Overall, older patients and those who are not yet retired were the demographic predictors for not having an improved discharge disposition. Others have shown that older age is a consistent predictor for readmission after colorectal surgery.(11) The capacity of the Romanian healthcare system is under pressure, due to limited financial resources, the demographic transition of the population and higher rates of cancer (12), and findings from this study indicate that older patients discharged from the hospital are more likely to have an inadequate discharge outcome, thus limiting the wellbeing of these patients in the long-term. In line with previous studies, those who were not retired were more likely to have a worsening state of health. This could be explained by previous research showing that these patients were more likely to have at least one risk factor than those who were retired.(13)

From the results, it is clear that colorectal surgery with the possible postoperative complications and delayed recovery, discharge from the surgical unit and could be used as predictors for the wellness at discharge. The overall morbidity rate of colorectal surgery was reported to be as high as $25 \%$, while for surgical emergencies, the rate can increase to up to $48.3 \%$. $(14,15)$ Even though we did not replicate previously reported research, our results could be explained by the higher rate of colorectal cancer patients that need emergency surgery, although there is a lack of data in the literature about the association of admission for medical-surgical emergencies and discharge disposition. Additionally, because data referring to the curative or palliative intent of the surgery was not available, we did not consider this information. Due to this result, we might consider that the health status of the patient at discharge can depend on the technical conduct of the operation and surgical volume. Moreover, these results may indicate the utilization of less intrusive surgical approaches (i.e., local excision) in the elderly. 
PUBLIC HEALTH AND MANAGEMENT

\begin{tabular}{|c|c|c|c|c|c|c|}
\hline \multirow{2}{*}{ Predictor independent variable } & \multirow{2}{*}{$\begin{array}{l}\text { Regression } \\
\text { coefficient }\end{array}$} & \multirow{2}{*}{$\chi^{2}$} & \multirow{2}{*}{ Variable for comparison } & \multicolumn{3}{|c|}{ Confidence level of $95 \%$} \\
\hline & & & & Inferior & $\operatorname{Exp}(B)$ & Superior \\
\hline Males & .089 & .262 & Females & .935 & 1.094 & 1.278 \\
\hline Age equal to or over 60 years & .380 & .002 & Age under 60 years & 1.147 & 1.463 & 1.865 \\
\hline Not retired patients & .309 & .004 & Retired patients & 1.106 & 1.363 & 1.679 \\
\hline Urban area & -.045 & .598 & Rural area & .807 & .956 & 1.131 \\
\hline Admission for medical-surgical emergencies & -.098 & .419 & Admission for other criteria & .715 & .907 & 1.150 \\
\hline Admission to surgical section & .333 & .054 & Admission to non-surgical section & .994 & 1.395 & 1.957 \\
\hline Discharge from surgical section & 1.039 & .000 & Discharge to non-surgical section & 1.934 & 2.827 & 4.134 \\
\hline Surgical procedure performed & 1.899 & .000 & Surgical procedure not performed & 5.041 & 6.610 & 8.666 \\
\hline Hospitalisation duration less than 7 days & 0.980 & .000 & $\begin{array}{l}\text { Hospitalisation duration equal to or } \\
\text { more than } 7 \text { days }\end{array}$ & 2.106 & 2.664 & 3.369 \\
\hline
\end{tabular}

Our findings suggest that for a successful discharge outcome, performing colorectal cancer surgery is one of the most important predictors for the outcome of discharge.

Another significant predictor for a successful discharge outcome was a long duration of hospitalization. In our sample, all patients had a mean length of hospitalization of around eight days. However, this difference in the length of stay could contribute to the outcome disparities between patients and lack of optimization inpatient care. Although for the majority of patients, early discharge could improve the overall recovery experience, it is essential to consider this approach from the point of feasibility and patient safety. In the case of a short hospitalization, it is important to coordinate outpatient monitoring, especially in those who had a surgical procedure and are in the postoperative period. However, the facilities that want to facilitate earlier discharge need to uptake short-stay protocols.(16) In the literature, higher hospital volume, as in our case, was associated with a length of stay reduction. It was found that a longer length of stay is associated with an increased risk of 30-day readmission.(17) Although a prolonged LOS is often associated with postoperative complications, advanced age and preoperative comorbidity (18), our findings on early discharge raise concerns about the risk for the health state of patients at discharge, and consequently on rates of readmission and postoperative morbidity. However, this finding requires further evaluation.

\section{CONCLUSIONS}

We have identified novel and potentially actionable demographic and hospital-level characteristics that can predict poor colorectal cancer outcomes at discharge in a Romanian hospital. More importantly, in this work, we identified contextual gaps in outcomes between certain demographic groups and medical services offered to these patients. Hospitals need to take into consideration these predictors and to direct additional interventions and resources for improving morbidity, mortality and other patient outcomes. By having the capacity to predict during the stay the discharge outcome after a specific hospitalization period for colorectal patients, we can increase the effectiveness of the patient management at these facilities.

\section{REFERENCES}

1. Ferlay J, Colombet M, Soerjomataram I, Dyba T, Randi G, Bettio M, et al. Cancer incidence and mortality patterns in Europe: Estimates for 40 countries and 25 major cancers in 2018. Eur J Cancer (Internet). 2018;103:356-87. Available from: https://doi.org/10.1016/j.ejca.2018.07.005.

2. Rabeneck L, Chiu HM, Senore C. International Perspective on the Burden of Colorectal Cancer and Public Health Effects. Gastroenterology (Internet). 2020;158(2):447-52. Available

from: https://doi.org/10.1053/j.gastro.2019.10.007.

3. Bray F, Ferlay J, Soerjomataram I, Siegel RL, Torre LA,
Jemal A. Global cancer statistics 2018: GLOBOCAN estimates of incidence and mortality worldwide for 36 cancers in 185 countries. CA Cancer J Clin. 2018;68(6):394-424.

4. Ionescu EM, Tieranu CG, Maftei D, Grivei A, Olteanu AO, Arbanas T, et al. Colorectal Cancer Trends of 2018 in Romania-an Important Geographical Variation Between Northern and Southern Lands and High Mortality Versus European Averages. J Gastrointest Cancer (Internet). 2020; Available from: https://doi.org/10.1007/s12029-020-003823.

5. McCann A, Sorensen J, Nally D, Kavanagh D, McNamara DA. Discharge outcomes among elderly patients undergoing emergency abdominal surgery: registry study of discharge data from Irish public hospitals. BMC Geriatr. 2020;20(1):72.

6. Ommundsen N, Nesbakken A, Wyller TB, Skovlund E, Bakka AO, Jordhøy MS, et al. Post-discharge complications in frail older patients after surgery for colorectal cancer. Eur J Surg Oncol (Internet). 2018;44(10):1542-7. Available from: https://doi.org/10.1016/j.ejso.2018.06.024.

7. Kim S, Lee SC, Skinner CS, Brown CJ, Balentine CJ. A Surgeon's Guide to Treating Older Patients with Colorectal Cancer. Curr Colorectal Cancer Rep. 2019;15(1).

8. Lee MTG, Chiu CC, Wang CC, Chang CN, Lee SH, Lee $\mathrm{M}$, et al. Trends and Outcomes of Surgical Treatment for Colorectal Cancer between 2004 and 2012- A n Analysis using National Inpatient Database. Sci Rep (Internet) 2017;7(1):1-8. Available from: http://dx.doi.org/10.1038/s41598-017-02224-y.

9. Mohanty S, Liu Y, Paruch JL, Kmiecik TE, Cohen ME, Ko $\mathrm{CY}$, et al. Risk of discharge to postacute care: A patientcentered outcome for the American College of Surgeons National Surgical Quality Improvement Program surgical risk calculator. JAMA Surg. 2015;150(5):480-4.

10. Saini SD, Vijan S, Schoenfeld P, Powell AA, Moser S, and Kerr EA. Role of quality measurement in inappropriate use of screening for colorectal cancer: Retrospective cohort study, $\quad$ BMJ. 2014;348 $\quad$ Feb:1-8 https://doi.org/10.1136/bmj.g1247.

11. Damle RN, Alavi K. Risk factors for 30-d readmission after colorectal surgery: A systematic review. J Surg Res (Internet). 2015;200(1):200-7. Available from: http://dx.doi.org/10.1016/j.jss.2015.06.052.

12. Vladescu C, Scintee SG, Olsavszky V, HernandezQuevedo C, Sagan A. Romania: Health System Review. Health Syst Transit (Internet). 2016;18(4):1-170. Available from: http://www.ncbi.nlm.nih.gov/pubmed/27603897.

13. Dodd N, Carey M, Mansfield E. Knowledge of colorectal cancer risk factors and screening recommendations: A crosssectional study of regional Australian general practice patients. Public Heal Res Pract. 2017;27(5):0-3 


\section{PUBLIC HEALTH AND MANAGEMENT}

14. Ommundsen $\mathrm{N}$, et al. Post-discharge complications in frail older patients after surgery for colorectal cancer, Eur J Surg Oncol. 2018;44(10):1542-1547. doi: 10.1016/j.ejso.2018.06.024.

15. Greco M, Capretti G, Beretta L, Gemma M, Pecorelli N, Braga M. Enhanced recovery program in colorectal surgery: a meta-analysis of randomized controlled trials. World J Surg. 2014;38:1531-1541. https://doi.org/10.1007/s00268-013-2416-8.

16. Price BA, Bednarski BK, You YN, Manandhar M, Dean EM, Alawadi ZM, et al. Accelerated enhanced Recovery following Minimally invasive colorectal cancer surgery (RecoverMI): A study protocol for a novel randomised controlled trial. BMJ Open. 2017;7(7):1-6.

17. Pucciarelli $\mathrm{S}$, et al. In-hospital mortality, 30-day readmission, and length of hospital stay after surgery for primary colorectal cancer: A national population-based study, Eur J Surg Oncol. 2017;43(7):1312-1323. https://doi.org/10.1016/j.ejso.2017.03.003.

18. Bartlett EK, Hoffman RL, Mahmoud NN, Karakousis GC, Kelz RR. Postdischarge occurrences after colorectal surgery happen early and are associated with dramatically increased rates of readmission. Dis Colon Rectum. 2014;57:1309-16. 